\title{
RESISTÊNCIA AOS NÚMEROS: A FAVELA COMO REALIDADE (IN)QUANTIFICÁVEL
}

\author{
Eugênia Motta ${ }^{1}$ \\ ${ }^{1}$ Universidade do Estado do Rio de Janeiro, Rio de Janeiro, RJ, Brasil
}

\section{Apresentação}

Os números, assim como as palavras, são formas de expressar e fazer existir (Desrosières \& Kott 2005), de conceber o mundo onde nos movemos e de transformá-lo. Este texto trata de "grandes números" (Desrosières 1993) ou "números públicos" (Porter 1995): as estatísticas estatais. Como afirma Theodore Porter, "[s]tatistics, preeminent among the quantitative tools for investigating society, is powerless unless it can make new entities" (1994:398). Discuto aqui a produção de uma entidade específica, a favela, baseada em algumas das operações envolvidas na sua criação e uso como realidade estatística e, portanto, como objeto de certo tipo de agência.

Consideram-se realidades aqui aqueles arranjos de elementos e relações que as pessoas reputam como existentes, relativamente autônomos e externos às subjetividades, observáveis, tangíveis e inteligíveis e, portanto, referências comuns, nos dois sentidos do termo comum: compartilhado e ordinário. Dessa forma, não apenas faz sentido, mas também se torna obrigatório considerar o termo no plural.

Além de serem um dos principais modos modernos de produção de conhecimento social, esses tipos de números são uma forma privilegiada de realidade estatal, constituindo a referência segundo a qual diversas agências são mobilizadas no esforço de se governar (Neiburg 2011; Cohn 1996; Mitchell 2002). Ocupam um lugar fundamental na construção das unidades, dos objetos e dos domínios de ação a partir do estado, mas não são puramente estatais.

A produção das estatísticas se dá ao longo de extensas cadeias de transformações (Thevenot 1995) que envolvem acordos, convenções, negociações, traduções e codificações (Desrosières \& Kott 2005). Ao esforço de quantificar se opõem dificuldades para se classificar - pessoas, coisas, 
espaços - para se levantarem dados e, depois de prontos os números - na forma de gráficos, tabelas, textos analíticos - eles sofrem contestações sobre a sua acuidade. São essas dimensões críticas da produção da realidade estatística que interessam aqui.

Meu principal objetivo é mostrar a relação entre as dificuldades e os obstáculos envolvidos na quantificação e a concepção das favelas como espaços anormais (ou subnormais), problemáticos e perigosos. Ian Hacking chamou a atenção para a proximidade entre os dois sentidos da normalidade no desenvolvimento das estatísticas, na sua visão, uma das ideias mais importantes do século XX: "The normal stands indifferently for what is typical, the unenthusiastic objective average, but it also stands for what has been, good health, and for what shall be, our chosen destiny" (1990:169).

As favelas foram consideradas como lugares problemáticos desde o seu surgimento, no final do século XIX no Rio de Janeiro (Valladares 2000, 2005). A sua definição como forma de ocupação do espaço urbano e a definição de lugares específicos como favelas (ou não) são objeto de disputa, das quais as estatísticas sempre fazem parte. A centralidade desses lugares no debate público e na reflexão acadêmica brasileira mobiliza os números de diferentes formas, desde a demonstração sobre a grande proporção da população que nelas vive até o número de mortes por arma de fogo quando se trata da discussão sobre violência urbana e segurança pública, por exemplo.

Para analisar como as favelas foram e são construídas como objetos quantificáveis proponho colocar em diálogo diferentes materiais empíricos. O ponto de partida desta proposta são os dados etnográficos de pesquisa de campo que vem sendo feita em uma comunidade do conjunto de favelas do Complexo do Alemão, na Zona Norte do Rio de Janeiro. ${ }^{1}$ Também utilizo documentos do Instituto Brasileiro de Geografia e Estatísticas (IBGE) ${ }^{2}$ referentes a diferentes censos populacionais, e dados sobre um levantamento populacional e geográfico feito em outra grande favela da cidade, a Maré.

Com essas diferentes bases é possível tratar de algumas das várias dimensões do processo de criação de realidades estatísticas. A interpretação etnográfica não se limita ao produto da observação participante situada (que está fortemente presente), mas é uma perspectiva que pretende tratar (ou propor uma interpretação que considere) a interconexão entre práticas e significados difusos, relativos a mundos sociais em princípio distantes, nos quais há diferentes concepções e experiências (como os gestores públicos responsáveis pela metodologia do censo e os moradores das favelas, por exemplo). Minha proposta é investigar a produção de realidades, os 
diversos esforços, oposições, operações práticas e simbólicas para a criação de um acordo (instável): a existência de algo concreto, inteligível, singular e coerente com outra série de coisas e relações.

Os obstáculos e as dificuldades são reveladores de importantes dimensões dos processos de quantificação, porque expressam de maneira aguda a grande quantidade de agentes, instâncias e esferas em que eles ocorrem. Analiso neste texto três tipos de oposições à quantificação que chamo de resistências. A ideia de resistência usada aqui não se define, como propõe James Scott (1985), por exemplo, pelas disputas de sentido promovidas por populações marginalizadas, embora, como mostro no texto, haja uma modalidade de resistência que se aproxima disso. Tomo resistência em um sentido mais próximo da física, como aquelas forças que se opõem ao esforço, ao trabalho, não sendo fruto, necessariamente, de uma ação intencional de algum agente.

O uso dessa ideia tem por objetivo chamar a atenção para a relação entre dinâmicas diferentes, mas que têm em comum apresentar oposições, demandar soluções e, por isso, mobilizam pessoas e instituições. O que resiste são os próprios objetos da quantificação enquanto são criados. É a disposição desordenada das casas nos morros, os movimentos de pessoas e das casas, a descrença dos moradores das favelas. Cada forma de resistência tratada corresponde à contraposição a um aspecto crucial das realidades estatísticas: mensurabilidade, estabilidade e anuência (ou acordo).

O texto está dividido em três partes, cada uma dedicada a uma forma de resistência da favela aos números. Na primeira, discuto, a partir da categoria "aglomerado subnormal", usada para tratar das favelas nas estatísticas oficiais, como se produziu uma certa concepção sobre pobreza - espacializada - a partir da construção desses espaços como difíceis de serem contados. Trata-se, portanto, de discutir a concepção, por meio da quantificação, da pobreza como realidade, ou seja, como algo existente, compreensível e sobre o que se pode (e se deve, neste caso) agir. Ao comparar o lugar da favela em três censos (de 1950, 1991 e 2010), mostro o nexo entre a normalização da favela como categoria e a ideia de que esses eram lugares nos quais e sobre os quais era - e é - difícil se produzirem números.

Em seguida, tratarei da categoria "domicílio", uma realidade estatística que se baseia na imobilização e na estabilização de pessoas e casas, fundamental na construção da estatística populacional. Ao esforço de se construírem essas unidades discretas se opõe o movimento constante que produz as casas como realidades vividas pelos moradores da favela. Esses espaços são difíceis de serem contados porque neles há muito movimento. 
Depois, discuto um tipo de resistência que se apresenta explicitamente por meio da contestação dos dados populacionais. Sugiro uma análise sobre os argumentos e as justificativas para a realização de uma autocontagem, feita por organizações locais de um enorme conjunto de favelas, a Maré. A realidade estatística produzida pelos órgãos oficiais é vista como falsa por algumas pessoas porque baseada em metodologia ao mesmo tempo inadequada e pautada em preconceito e estigmatização. Produzir seus próprios números, segundo os organizadores do Censo local, é disputar a forma pela qual a favela é percebida publicamente e tratada pelos agentes estatais.

\section{Favelas: problemas desde a origem}

A primeira favela surgiu no final do século XIX em uma encosta próxima ao centro da cidade do Rio de Janeiro. De acordo com a narrativa mais aceita - um verdadeiro mito de origem, segundo Licia Valladares (2000) - o primeiro lugar ocupado foi o Morro da Favella. A existência de casas feitas de materiais reaproveitados, construídas de forma desalinhada por pessoas consideradas pobres e não proprietárias legítimas da terra que ocupavam logo se tornou uma questão pública. O nome próprio do morro ocupado de forma pioneira se tornou um substantivo comum, correspondente a um tipo de lugar que carregaria essas mesmas características.

Mais de um século depois de seu surgimento, as favelas cresceram em número e tamanho e continuam sendo vistas publicamente e tratadas pelos agentes estatais como problemas para os quais é preciso tomar medidas. Paradoxalmente, um dos principais argumentos usados repetidamente para justificar sucessivas intervenções estatais é de que estes são espaços onde sempre faltou estado.

Ao longo do século XX foram elaboradas várias soluções para o recorrente "problema da favela" (Machado da Silva 2002). O primeiro tipo de preocupação expressa era com a suposta feiúra causada pelo "câncer" estético que esses lugares representavam. Também foram consideradas lugares insalubres, onde facilmente se disseminavam doenças, representando uma ameaça à saúde dos citadinos. Ao mesmo tempo foram e até hoje são vistas como expressão de um problema habitacional, por causa da falta de acesso a moradias baratas para a população com baixa renda.

A intervenção proposta - e em parte executada - nos anos 1960 e 1970 foi a sua extinção, com a desocupação das casas e sua demolição. Mas as favelas continuaram a existir e crescer. Em 1980 a política escolhida foi a 
de urbanização, com a proposta de melhoramento da infraestrutura nesses locais, com obras de saneamento, pavimentação de ruas, entre outras medidas (Burgos 1998).

Mais recentemente, em especial a partir dos anos 1990, as favelas foram consideradas como o principal lócus de produção da violência urbana (Machado da Silva 2010). Com a instalação de grupos armados responsáveis pela venda a varejo de drogas proibidas e a forte dimensão territorial de seu poderio, as intervenções policiais têm sido, desde então, a tônica das políticas voltadas para estes espaços.

A associação com a pobreza também começou cedo. Por algum tempo a produção universitária sobre as favelas esteve intrinsecamente ligada a esta questão, de modo que aqueles que faziam pesquisa em favelas quase sempre estudavam pobreza - e o lugar para se estudar a pobreza urbana eram as favelas (Valladares 2000).

As intervenções mais recentes nas favelas da cidade, na segunda metade dos anos 2000, foram as obras feitas por meio do Programa de Aceleração do Crescimento (PAC) e a instalação das Unidades de Polícia Pacificadora (UPP). Os dois programas representam, justamente, as duas vertentes de tratamento que a favela vem recebendo dos governos estatais. Por meio do PAC houve intervenções para a construção de infraestrutura urbana, acompanhadas de políticas chamadas de "sociais". As novas unidades de polícia foram apresentadas como uma distinta modalidade de "política de segurança" e, por alguns anos, fizeram cessar os enfrentamentos armados que, porém, voltaram a ocorrer recentemente.

\section{Da favela ao aglomerado subnormal: a pobreza como realidade especializada}

Nesta seção analiso os usos das categorias "favela" e "aglomerado subnormal" nos documentos do IBGE referentes a três censos populacionais: o de 1950, primeiro a contabilizar os moradores de favelas; o de 1991, que inaugurou o uso do termo "aglomerado subnormal", e o último, realizado em 2010.

Com base nos dados do levantamento populacional feito de maneira pioneira em 1950, o IBGE produziu um documento de análise dos dados. A dificuldade de se levantarem os dados foi expressa da seguinte maneira, em comparação com outros lugares da cidade:

Nas favelas, o levantamento predial-domiciliário processou-se em geral do mesmo modo que nas demais áreas, mas encontrou tarefas de natureza di- 
ferente e que demandaram maiores esforços para sua execução. O terreno a percorrer nem sempre permitiria fácil acesso, exigindo, ao contrário, trabalho árduo por parte do locador para o completo reconhecimento (IBGE, 1953:18).

O documento também aponta para as dificuldades em se propor uma definição objetiva para esses lugares. A escolha do IBGE partiu daquilo que os técnicos chamaram de "consenso social", ou seja, consideraram como favelas, em princípio, os lugares que comumente eram conhecidos desta forma. Baseado nesse levantamento, o instituto propôs a seguinte definição:

Desse modo, foram incluídos na conceituação de favela os aglomerados humanos que possuíssem, total ou parcialmente, as seguintes características:

1. Proporções mínimas - Agrupamentos prediais ou residenciais formados com unidades de número geralmente superior a 50; 2. Tipo de habitação Predominância, no grupamento, de casebres ou barracões de aspecto rústico típico, construídos principalmente de folhas de flandres, chapas zincadas, tábuas ou materiais semelhantes; 3. Condição jurídica da ocupação - Construções sem licenciamento e sem fiscalização, em terrenos de terceiros ou de propriedade desconhecida; 4. Melhoramentos públicos - Ausência, no todo ou em parte, de rede sanitária, luz, telefone, e água encanada; 5. Urbanização - Área não urbanizada, com falta de arruamento, numeração ou emplacamento (IBGE 1953).

Em 1991 o IBGE incorporou no censo a categoria "aglomerado subnormal", que é um tipo de "setor censitário". ${ }^{3}$ Estas duas categorias são chamadas de "operacionais". Isso quer dizer que se referem à coleta dos dados e não à sua organização lógica e analítica. Um setor censitário é uma área definida a partir da capacidade de um único recenseador realizar todas as atividades referentes ao levantamento dos dados em um certo intervalo de tempo. A definição de aglomerado subnormal é a seguinte:

O setor especial de aglomerado subnormal é um conjunto constituído de, no mínimo, 51 (cinquenta e uma) unidades habitacionais (barracos, casas...) carentes, em sua maioria, de serviços públicos essenciais, ocupando ou tendo ocupado, até período recente, terreno de propriedade alheia (pública ou particular) e estando dispostas, em geral, de forma desordenada e densa. A identificação dos Aglomerados Subnormais deve ser feita com base nos seguintes critérios: a) Ocupação ilegal da terra, ou seja, construção em terrenos de propriedade alheia (pública ou particular) no momento atual ou em período recente (obtenção do título de propriedade do terreno há dez anos ou menos); e b) Possuírem pelo menos uma das seguintes características: 
urbanização fora dos padrões vigentes - refletido por vias de circulação estreitas e de alinhamento irregular, lotes de tamanhos e formas desiguais e construções não regularizadas por órgãos públicos; e precariedade de serviços públicos essenciais (IBGE 2011:27).

A definição de aglomerado subnormal é claramente baseada na definição de favela dos anos $1950 .{ }^{4}$ Em ambas são destacados a falta de urbanização e um regime não legal de propriedade dos terrenos como principais características. A diferença entre as duas é que a expressão mais antiga dizia respeito à descrição posterior de uma realidade externa às estatísticas. No segundo caso, caracteriza-se um tipo lugar, cujos traços são um problema para a pesquisa de campo.

Os aglomerados subnormais, ao lado de outros espaços, como aldeias indígenas e presídios, por exemplo, eram definidos como uma unidade referida justamente à suposta dificuldade de se recolherem informações no campo. ${ }^{5}$ As dificuldades que esses espaços apresentam para a contagem da população é uma das modalidades do que chamo de resistência. São lugares que resistem à categorização e ao levantamento dos dados, seja em parte pela dificuldade de se circular dentro deles, no caso das favelas, seja pelo fato de não constituírem moradias de tipo familiar, como no caso de cadeias e quartéis, o que os torna "especiais".

A partir de 2010, quando foi feito o último censo nacional, a categoria passa a ser considerada de maneira diferente daquela dos outros levantamentos e começa a ser tratada como unidade de análise. O IBGE divulgou, como parte dos resultados da pesquisa, um documento específico que trata dos aglomerados subnormais em todo o Brasil. Há mapas e tabelas sobre os dados populacionais desses setores, agregados por estados e regiões. Houve uma mudança, inclusive em referência às unidades espaciais às quais o termo se refere: um aglomerado subnormal, que tem um nome referido ao nome usual do lugar (o Morro do Alemão, por exemplo), pode ser composto por vários setores censitários. ${ }^{6}$

Estas três formas de incorporação das favelas à estatística pública são enquadramentos distintos sobre o que são esses espaços em relação ao próprio esforço de contar como prática rotineira - a coleta de dados - e em relação ao seu lugar no conjunto de unidades e categorias do censo em geral. Partindo de uma definição comum sobre a favela, a primeira forma de incorporação é resultado de um esforço de ida a campo exploratória, a partir da qual se procura definir tecnicamente o que ela seja. O aglomerado subnormal, como categoria operacional, é uma ampliação da noção de favela a partir de um deslocamento em relação à especificidade do Rio de Janeiro que aponta para a dificuldade específica de se realizar o próprio levantamento. 
Em 2010, a categoria foi transformada de operacional em um tipo particular de unidade de análise que transgride a forma mais comum de agregação sucessiva em unidades cada vez mais amplas e que correspondem à soma, e somente à soma, de uma quantidade definida de elementos do tipo imediatamente anterior. Diferentemente disso, apresentar os dados populacionais de aglomerados subnormais por estado, por exemplo, implica considerar que esses lugares são um mesmo tipo de espaço - entendido também como um agregado de pessoas - cuja identidade permite (ou obriga a) transpassar a lógica do englobamento sucessivo de unidades espaciais contíguas.

As três formas de enquadramento mostram, por um lado, uma resistência persistente da favela à quantificação, demonstrada pela normalização progressiva por meio de uma tipificação anormalizadora. A ideia de favela é alargada e objetivada de maneira a se aplicar não apenas à realidade do Rio de Janeiro e é apresentada como uma forma recorrente - e normal, em um sentido - ao mesmo tempo em que se torna uma categoria progressivamente mais abstrata de anormalidade, capaz de abarcar uma quantidade cada vez maior de casos.

A categoria aglomerado subnormal está longe de resumir ou abarcar tudo o que se trata como pobreza no Brasil. Mas a partir dela é possível reconhecer a centralidade da ideia de favela na construção da pobreza brasileira e, mais especificamente, de suas apresentações espacializadas.

A categoria aglomerado subnormal, sendo em grande medida uma generalização da ideia de favela, carrega em si a associação que esses espaços sempre tiveram com a pobreza e com a sua representação espacilizada. Duas características foram transportadas desde a categoria comum favela que o IBGE transformou em objeto de interrogação sistemática no censo de 1950 até o levantamento de 2010: a primeira delas é a desordem na disposição das casas e no traçado das ruas e dos caminhos, e a segunda é a ilegitimidade na ocupação dos terrenos, supondo-se a construção e a ocupação dos espaços pertencentes a outras pessoas ou entidades sem o consentimento destas últimas.

Essa operação de generalização estatística da favela como pobreza espacializada está presente no documento do IBGE de 1953 e nas operações analíticas feitas a partir dos dados do censo. O que se segue consta no início da apresentação dos dados. É uma advertência que segue princípios técnicos e delimita a possibilidade interpretativa no tempo e no espaço, fazendo especial referência aos limites dos dados em termos de generalização.

Assim, os resultados apresentados nas tabelas anexas não podem ser tomados como referentes a toda a população favelada do Distrito Federal. Eles dizem 
respeito, apenas, à população presente - que inclui os habitantes presentes em $1^{\circ}$ de julho de 1950, moradores ou não - nas favelas relacionadas no quadro $\mathrm{n}^{\circ} 7$ e representam, segundo se estima, $90 \%$ do total de habitantes das favelas cariocas, reconhecidas comumente como tais (IBGE 1953:16).

Outro trecho, que figura nas "Considerações Finais" do documento, aponta outro tipo de operação lógica:

[...] [O] que esses resultados revelam, antes de tudo, é um instantâneo da vida das populações pobres em geral, disseminadas por todas as regiões do país e cujos aspectos essenciais não deverão variar muito. Vale, portanto, tal instantâneo como uma amostra que indica os aspectos fundamentais de uma parte socialmente definida da população do Brasil, oferecendo ensejo para pesquisas úteis sobre o comportamento de determinados grupos sociais economicamente homogêneos, reunidos, sob condições particulares, em aglomerados numerosos (IBGE 1953:23).

A pobreza, espacializada e "favelizada" por meio da categoria aglomerado subnormal, atribui aos sujeitos contados apenas indiretamente um déficit, ao permitir inferir que as pessoas que moram nesses lugares têm pouco dinheiro. O que se destaca é um certo tipo de usurpação, ao definir como ilegítima ou ilegal a relação de propriedade com a terra.

\section{O domicílio como imobilização}

A realidade estatística populacional é feita de imobilizações. É preciso estabelecer relações exclusivas entre espaços e entre eles e as pessoas. A primeira estabilização operada por este tipo de quantificação, tanto em termos do levantamento de dados quanto da construção da lógica de leitura deles, é a associação entre pessoas e espaços por meio da ideia de moradia e gestão dos recursos de manutenção da vida comum. A categoria "domicílio" define a unidade de produção dos dados - preenche-se um questionário por domicílio - e é a primeira forma de agregação das informações sobre indivíduos que, somados, formam uma "população".

As formas sucessivas de agregação dos dados, a partir de categorias espaciais que se tornam mais amplas, cada nível sendo composto por uma dada quantidade de elementos do nível anterior, começam na definição do pertencimento exclusivo de cada pessoa a uma, e apenas a uma, unidade espacial e econômica determinada. Assim, uma quantidade de pessoas habita em um domicílio, uma quantidade de domicílios forma um setor censitário, uma quantidade de setores censitários, por sua vez, compõe um distrito. 
A definição de domicílio, segundo o IBGE, é a seguinte:

Local de moradia estruturalmente separado e independente, constituído por um ou mais cômodos. A separação fica caracterizada quando o local de moradia é limitado por paredes, muros, cercas etc., coberto por um teto, permitindo que os moradores se isolem, arcando com parte ou todas as suas despesas de alimentação ou moradia. A independência fica caracterizada quando o local de moradia tem acesso direto, permitindo que os moradores possam entrar e sair sem passar por local de moradia de outras pessoas. Os domicílios classificam-se em: domicílio particular ou domicílio coletivo (IBGE s/d:16, grifos meus).

A noção de domicílio opera a primeira fase de criação de uma população, ou seja, da ligação de uma quantidade de indivíduos a um determinado território, baseada no "isolamento" na gestão dos recursos necessários "à alimentação e à moradia". Ela abarca também a ideia de "família", configuração ideal desse conjunto de indivíduos. Uma das classificações dos domicílios se refere justamente ao estatuto familiar de seus moradores. Há, portanto, na realidade estatística do domicílio, relações definidas entre indivíduos, economia, família e espaços construídos.

O vínculo com a ideia de família tem importância na definição de um conceito que vem ocupando um papel central na discussão sobre políticas públicas no Brasil, que é o chamado "déficit habitacional". Ele é calculado a partir do número de "famílias" que moram na rua, mas o maior contingente se refere àquelas que habitam em lugares "inadequados", ou dividem um mesmo espaço com outra família. O ideal de que uma família, não mais que uma, deva corresponder a um domicílio tem forte participação na forma como se desenham, executam e avaliam grandes políticas.

Com base em uma etnografia feita em uma comunidade do conjunto de favelas do Complexo do Alemão, mostrarei a seguir como esses elementos se apresentam como parte de uma outra realidade, que é a das casas vividas na favela. Se no domicílio as relações são exclusivas, as unidades são discretas e estáveis, nessa outra realidade as relações e os elementos se caracterizam pela sua transformação constante e pelo movimento.

A discussão sobre a relação entre os números e a favela proposta aqui se inscreve na agenda mais ampla de uma antropologia da casa, cuja pretensão é colocar no centro da análise este elemento crucial na vida social. A antropologia deu atenção às casas com perspectivas diversas e para tratar de diferentes questões. Destaco a seguir três importantes vertentes.

A primeira delas diz respeito às preocupações em relação ao que se chama de cultura material, que dá relevo à participação dos espaços construídos, dos objetos e das substâncias nas relações (Miller 2001). Os chamados novos 
estudos do parentesco, por sua parte, são os que sugerem tomar a casa em suas múltiplas dimensões, como lócus e instituição privilegiados da construção de familiaridade (Marcelin 1996, 1999; Carsten 2003). Sua base em leituras subversivas da ideia de "maison" de Lévi-Strauss (1982, 1984, 1987, 1991) desafia a normatividade e a busca por modelos explicativos - que inquietaram este mesmo antropólogo, entre tantos outros - radicalizando a premissa de sua proposta de tomar o conceito nativo de casa como ponto de partida para a construção de uma nova base analítica sobre o parentesco (Carsten \& Hugh-Jones 1995). Uma outra referência fundamental são os estudos de antropólogos brasileiros que trouxeram uma nova perspectiva sobre questões sociológicas e políticas centrais na tradição do pensamento social e que dizem respeito às relações econômicas, de trabalho e de dominação no Brasil (Heredia 1979; Palmeira 1977; Garcia Jr 1975; Woortman 1980).

Essas diferentes tradições nos estudos sobre casa na antropologia ajudam a compreender as dinâmicas em torno das casas no Complexo do Alemão, especialmente naquilo em que esses diferentes elementos ou esferas da vida social se misturam e se combinam: as familiaridades, a transformação material dos espaços, o trabalho e a economia. Proponho, então, uma abordagem sobre as casas que se articula em torno de dois eixos analíticos.

O primeiro deles é a atenção à economia cotidiana (Motta 2016), ou seja, às práticas econômicas ordinárias das pessoas, a partir de um ponto de vista radicalmente etnográfico, o que tem como consequência considerá-las não apenas como embebidas que estão em relações de família, amizade, políticas, por exemplo, mas também como aspecto fundamental e inseparável delas e vice-versa. O segundo eixo diz respeito às formas de governo (Neiburg 2014; L'Estole 2014), especificamente no que se refere a discutir a construção das favelas como problema e da pobreza como realidade sobre a qual é preciso agir, mas também para compreender as formas pelas quais se fazem casas cotidianamente na favela.

Uma antropologia da casa, portanto, permite compreendê-la como processo cotidiano, sem deixar de levar em conta as diversas outras agências que participam de sua construção, além daquelas dos moradores, entre elas, a agência dos governos estatais. Ao colocar lado a lado, analiticamente, as duas realidades da casa - a realidade estatística como domicílio e a realidade vivida pelos moradores - pretendo mostrar como as resistências recíprocas são significativas na compreensão do que sejam as favelas.

As casas que observei na favela são construções indissociavelmente materiais e simbólicas em torno das quais grande parte da vida social tem lugar. Elas são o lugar do cuidado, da construção de corpos, de pessoas generificadas. São objeto de grande investimento financeiro e emocional 
das pessoas, cujas trajetórias, relações e perspectivas sobre o futuro se ligam intrinsecamente aos espaços. Transformam-se o tempo todo, materialmente e na imaginação das pessoas. As casas são constituídas pelos e nos movimentos da vida cotidiana e tratarei especificamente de três deles, que dialogam diretamente com as bases da concepção de domicílio como realidade estatística. Os dados etnográficos que se seguem são fruto de um trabalho de campo no Complexo do Alemão, conjunto de favelas na Zona Norte do Rio de Janeiro, iniciado em 2012 (Motta 2014).

Entre as coisas que mais circulam entre e nas casas está o dinheiro. Há uma expressão nativa sobre uma forma específica de separar e marcar os dinheiros, que é o "dinheiro da casa". Ele se define, na prática, a partir do tipo de fonte e do tipo de uso que se faz dele. É composto, em geral, por parte dos ganhos regulares ligados ao trabalho ou aos negócios, como os salários, por exemplo. Destina-se a dar conta das despesas com a manutenção da casa, em um sentido amplo. Serve para pagar gás de cozinha, luz, TV a cabo, internet, material de limpeza, comida. Essas despesas não se referem, porém, a uma unidade discreta. Todos esses gastos são parte da manutenção também de relações da casa com outras casas. Isto fica evidente quando se observa a compra de comida que, comumente, vai servir para preparar refeições para muitas outras pessoas além daquelas consideradas como moradores..$^{9}$ As crianças costumam ser os mais móveis entre as casas. Por exemplo, no caso da família que observei, elas fazem refeições nas casas dos avós durante a semana.

Entre as casas também são comuns os empréstimos e os presentes em forma de dinheiro, considerados, em grande parte das situações, como obrigações entre pessoas que se percebem ligadas por laços de família. Alguns autores mostram a importância da comida, das substâncias e das suas circulações na construção deste tipo de relação (Carsten 2003). No universo social que observei, o dinheiro também é um importante meio de se fazerem e de se manterem laços. Dinheiro da casa é dinheiro que faz família.

Os pais de uma jovem que engravida, por exemplo, se sentem obrigados a construir uma casa para a filha. Essa relação de origem entre casas está na base de uma organização hierárquica e cheia de moralidades que se transforma ao longo do tempo, mas que sempre envolve formas específicas de circulação de dinheiro. Portanto, o que está em jogo na realidade das casas vividas, notadamente no que diz respeito ao dinheiro, não são unidades discretas de referência, como supõe a realidade do domicílio. Essas casas na favela se constituem como tal não por meio do isolamento, mas pelas relações. Assim, utilizo a ideia de configuração de casas para tratar dessa constituição necessária das casas a partir de relações com outras. 
Louis Marcelin $(1996,1999)$ utiliza esta categoria para descrever arranjos compostos por diversas casas e sua relevância nas relações expressas pela linguagem de parentesco entre famílias negras do Recôncavo Baiano. A proximidade física entre as casas nesse universo etnográfico particular sugere que as casas componham unidades suficientemente evidentes para que o autor identifique o número delas que pode pertencer a uma dada configuração. Na favela onde fiz pesquisa de campo, casas que se relacionam em configuração não necessariamente ficam perto umas das outras. Isto se dá, principalmente, pelo intenso movimento das pessoas entre casas ao longo da vida. Pude observar que é muito comum que as pessoas se mudem com frequência entre casas na mesma comunidade.

As distâncias físicas são uma questão importante nas configurações, já que são condições práticas que interferem nas formas de circulação cotidiana de pessoas e objetos. Mas, diferente do observado por Marcelin na Bahia ou por Flavia Dalmaso no Haiti (2014), a contiguidade espacial não é uma característica necessária das configurações de casa na favela. Estes fatos me levaram a buscar no conceito de configuração de Norbert Elias (1980) uma releitura da noção formulada por Marcelin. Esses arranjos não são unidades existentes por si mesmas, mas visíveis a partir das circulações entre os elementos, relativamente autônomos, que as constituem. As relações entre elas não são simétricas, havendo uma marcada hierarquia entre as casas, relacionada aos laços de interdependência entre elas. Esses laços, por seu lado, não são plenamente estáveis, de modo que toda configuração é um arranjo mutável (Motta 2014).

As casas materiais também estão em constante movimento: são casas mutáveis. Além da anexação sucessiva de novos cômodos de acordo com os recursos disponíveis, as casas podem ser transformadas, por exemplo, em espaços de negócio. Uma sala pode se transformar em cabeleireiro, depois em loja de roupas e depois novamente em sala, como pude observar em um caso específico. Este tipo particular de mutabilidade é central nas estratégias para se ganhar dinheiro entre as pessoas com as quais fiz pesquisa de campo. Essa conversibilidade dos espaços da casa aumenta, inclusive, seu valor no mercado imobiliário da favela. Nem mesmo em seu aspecto que, à primeira vista, poderia parecer o mais estático - o aspecto material - a casa vivida é estável.

As pessoas também se transformam e circulam nas e entre as casas ao longo da vida e durante os dias e as noites. As práticas de cuidado e comensalidade são centrais na construção das relações vividas como relações entre parentes e amigos. Como pude perceber na pesquisa no Alemão - e como sugerem os chamados "novos estudos de parentesco" - elas são construídas no cotidiano e têm na casa sua principal referência espacial e simbólica. 


\section{A favela que conta a si mesma}

Nesta seção, tratarei de outro tipo de resistência, explicitada por sujeitos determinados, na forma de contestação dos números do censo. No caso de que trato a seguir, a resistência à quantificação se dirige especificamente aos dados estatísticos oficiais e é transformada em iniciativa de construção de números alternativos.

A Maré é uma enorme favela, plana na maior parte do seu território. Sua ocupação começou pelo uso autorizado pelo governo de áreas próximas à Avenida Brasil, tendo sido os operários que trabalhavam na sua construção seus primeiros moradores. A via expressa liga o Centro a uma parte do subúrbio e outros municípios conurbados. Foi nessa localidade que se deu a primeira inciativa de autorrecenseamento, que começou em 1999 e se concretizou por meio de um projeto do Centro de Estudos e Ações Solidárias da Maré - Ceasm (Silva 2002). O segundo Censo da Maré foi feito em 2011, por iniciativa de outras organizações, a Redes da Maré e o Observatório de Favelas. Além da contagem populacional, foi feita previamente uma atualização da base cartográfica da área e um Censo de Empreendimentos, que pretendeu fazer um levantamento dos negócios e dos empregos gerados pelas suas atividades (Observatório de Favelas; Rede de Desenvolvimento da Maré 2012)

Nas duas ocasiões, as justificativas para a necessidade de mobilizar moradores e organizações locais para realizar o levantamento de dados se davam em torno de dois tipos de argumentos. O primeiro era a incapacidade de as informações do IBGE darem conta das especificidades e das demandas reais dos moradores. O segundo dizia respeito à forma como a estigmatização, o preconceito e o desconhecimento de pesquisadores estranhos à comunidade impediam uma pesquisa bem feita. Nas enunciações mais formalizadas, como a que se segue, as duas coisas aparecem necessariamente articuladas.

Ainda persistem inúmeros vieses metodológicos nas pesquisas realizadas em favelas. A maior parte provém da imprecisão das bases cartográficas, mas não há como ignorar, também, a existência de vieses decorrentes de juízos sobre a favela que afetam desde o planejamento da pesquisa até a realização da entrevista, como a construção de pressupostos marginalizantes que dificultam ou impedem a abordagem do público. O processo de estigmatização é um dos inúmeros reflexos históricos de como as favelas vêm sendo concebidas e representadas, desde o seu aparecimento, em diferentes campos do imaginário social (FBB s/d).

Este tipo de resistência mobiliza discursivamente os dois outros tipos a que me referi nos itens anteriores deste texto: a associação entre desordem espacial, pobreza e movimento e a ilegitimidade na apropriação dos espaços. 
Claro que, diferentemente do que pretende um texto analítico, as organizações da Maré constroem argumentos políticos e morais para justificar o esforço de se criarem novas estatísticas.

Embora a crítica às estatísticas oficiais possa ter sido ferrenha por vezes, a produção do Censo da Maré teve a participação de vários órgãos de governos estatais. A Escola Nacional de Ciências Estatísticas (Ence), que pertence ao IBGE, e o Instituto Pereira Passos (IPP), da Prefeitura do Rio de Janeiro, são citados como "parceiros" do projeto, financiado por meio de uma verba da Fundação do Banco do Brasil, este um banco estatal.

A relação com estes órgãos é um sinal de algo que atravessa as dinâmicas de crítica e produção de dados alternativos, que é a ambiguidade entre o reconhecimento da relevância e da existência real das realidades das estatísticas, combinada a uma desconfiança permanente em relação a elas. Há aqui principalmente a ideia de que a estatística é a realidade percebida pelos agentes estatais e que, portanto, é preciso disputá-la. Como resumiu uma ativista do Complexo do Alemão, que considera a população do local muito maior do que aquela que foi apurada pelo censo: "Menos população, menos investimento".

Se, por um lado, o objetivo era adaptar a metodologia às especificidades locais, também houve o movimento contrário. A equipe da pesquisa do Censo Maré, em 2010, percorreu toda a área e, além de corrigir os mapas oficiais que estavam desatualizados, propôs que se organizassem os moradores para que dessem nome às ruas que ainda não tinham. Nesse processo, além de retificar as informações oficiais, também houve uma adaptação do próprio local aos critérios formais, entre os quais está a nomeação das ruas. O mapeamento, portanto, é um processo recíproco de transformação entre realidade estatística e realidade cotidiana.

A quantificação e o tipo de ordem que ela implica não são apenas ideais normativos estatais que "anormalizam" resistências. O Censo da Maré mostra que a realidade estatística pode ser uma forma de valorização moral e política da favela que ocorre por meio da incorporação de alguns de seus princípios de ordem e rigor às práticas de militância - como objeto da luta política - e de vivência dos espaços - como colocar nomes nas ruas, por exemplo.

\section{Considerações finais: realidades que contam}

Acompanhei durante dois anos, na minha pesquisa de doutorado, o cotidiano de construção de um sistema de informações estatísticas. Com a criação da Secretaria Nacional de Economia Solidária, em 2003, foi necessário pro- 
duzir um sistema de informações que pudesse servir de base para políticas na área. O conceito "economia solidária" não fazia parte da administração pública nacional até aquele momento. Era preciso criar a realidade que seria objeto de intervenção. Foram anos, centenas de reuniões, acusações, brigas sobre como produzir essas informações. O argumento de grande parte dos envolvidos era de que seria impossível quantificar a economia solidária e, mais que isso, que era um reducionismo violento, que colocava em risco aquilo que lhe era mais característico. No lançamento da publicação preparada para divulgar os primeiros dados da pesquisa estatística, que foi afinal realizada, eu estava preocupada. Vários dos mais ferrenhos opositores do chamado mapeamento estavam presentes na cerimônia. Um deles compunha a mesa do evento e falaria para a plateia em um auditório lotado. Começou sua fala empunhando o livro, sacudindo-o na direção do público e disse: "Está aqui! Agora nós existimos!" (Motta 2010).

Esse episódio mostra que o esforço de contestação da possibilidade de quantificação, sempre baseado no argumento de que a realidade não cabe em números, é parte da construção lógica da sua validade, já que estes precisam ser constituídos, eles próprios, como realidade. Quando suficientemente separada de outras realidades, ela pode se apresentar como autônoma, coerente, comum e tangível. Como sugere Porter (1995), "quantification is a technology of distance". As resistências à quantificação são jogos de distanciamento e aproximação entre realidades e, por isso, um ângulo privilegiado para se observar a construção das estatísticas.

As dificuldades em se fazer o levantamento dos dados, de se classificar certo tipo de espaço, e de gerar confiança nos números estão relacionadas entre si. Esta é outra razão pela qual a ideia de resistência para tratar de diferentes dinâmicas sociais parece ser adequada. Ela permite enxergar as relações entre operações práticas e lógicas do processo de quantificação. A ideia de "cadeia de transformações", como apresentada por Thévenot (1995) é bastante útil ao frisar as diferentes operações e os distintos tipos de investimentos necessários para a produção dos números. Da perspectiva proposta aqui, porém, a linearidade que essa imagem supõe é colocada em xeque. As resistências evidenciam as relações recíprocas e contínuas entre os procedimentos envolvidos na produção das estatísticas.

Pensar sobre as estatísticas implica pensar sobre o governo estatal e suas formas de agência. A partir delas e dos estudos das relações tensas entre elas e outras realidades, o caráter processual e distribuído das formas de governo se revela. As categorias estatais, os dados estatísticos não são instrumentos prontos de imposição de um poder centralizado, mas são resultados, sempre provisórios, de negociações entre agências diversas. 
Procurei explorar no texto a possibilidade de aproximar diferentes lógicas e escalas de análise. Ao identificar a transformação da ideia de favela nos censos populacionais brasileiros e o lugar fundamental da ideia de imobilização a partir dos domicílios, busquei mostrar que a forma como as pessoas constroem as casas e o modo como as vivem estão ligados, são relevantes e são objeto de ação e preocupação não apenas dos moradores. Procuro, com base nas estratégias analíticas apresentadas neste artigo, colocar em relação questões que comumente são tratadas pelas ciências sociais de forma separada: a vida doméstica e familiar, as políticas públicas, as disputas políticas por reconhecimento.

Um aspecto fundamental dos números públicos que explorei apenas superficialmente é a sua capacidade de transformar outras realidades. Seja por meio da incorporação dos modelos lógicos, como a nomeação das ruas (que é uma forma específica de classificação) na Maré, seja como critério para a construção de condomínios para a chamada "habitação social", as estatísticas são realidades tanto mais reais quanto mais participem da construção das condições para se agir sobre outras realidades.

Os processos de produção de estatísticas públicas, as resistências, as negociações e as incorporações se dão em torno das formas de classificar e enquadrar pessoas, espaços e relações. Tratar deste tipo de quantificação, portanto, é tratar das dinâmicas em torno da definição sobre quais são as realidades que (se) contam.

Recebido em: 07/02/2019

Aprovado em: 25/02/2019

\section{Eugênia Motta}

Mestre e doutora pelo Programa de Pós-graduação em Antropologia Social do Museu Nacional (UFRJ), pesquisadora do Núcleo de Pesquisas em Cultura e Economia (NuCEC) desde a sua fundação em 2004, uma das coordenadoras do Grupo CASA - Estudos Sociais sobre Moradia e Cidade, e conselheira do Instituto Raízes em Movimento, organização com sede no Morro do Alemão. Atualmente é professora colaboradora e bolsista de pós-doutorado (PNPD/ Capes) no Programa de Pós-graduação em Sociologia do Instituto de Estudos Sociais e Políticos da Universidade do Estado do Rio de Janeiro (Iesp / Uerj). 


\section{Notas}

1 Por razões que já devem ter ficado claras, é problemático apresentar dados estatísticos com qualquer objetivo descritivo neste texto. Mas há que se reconhecer a importância deste tipo de dado como elementos relevantes dos argumentos dos textos das ciências sociais. Suspendo por um momento a análise sobre os números para apresentar alguns deles como informação ao leitor. De acordo com a Prefeitura do Rio de Janeiro, cerca de 60.500 pessoas vivem no Complexo do Alemão em aproximadamente 18.000 domicílios (Cavallieri \& Vial 2012)

2 O Instituto Nacional de Estatística foi instituído legalmente em 1934 e instalado em 1936, em 1938 passando a se chamar IBGE. Hoje em dia está subordinado ao Ministério do Planejamento, Orçamento e Gestão, do governo federal.

3 “O setor censitário é a unidade territorial estabelecida para fins de controle cadastral, formado por área contínua, situada em um único quadro urbano ou rural, com dimensão e número de domicílios que permitam o levantamento por um recenseador. Assim sendo, cada recenseador procederá à coleta de informações tendo como meta a cobertura do setor censitário que lhe é designado." (IBGE, Guia do Censo 2010. Disponível em http://censo2010. ibge.gov.br/materiais/guia-do-censo/operacao-censitaria.html). Em todo o Brasil são aproximadamente 314.000 setores censitários.

4 A relação entre as categorias não é evidente apenas do ponto de vista lógico. O código interno usado para aglomerado subnormal nos documentos do instituto é "FAV" (IBGE 2003:284).

$5 \mathrm{O}$ "setor especial de aglomerado subnormal" é um tipo "setor especial" definido como "aquele que apresenta características que tornam necessário um tratamento diferenciado de coleta em relação aos setores comuns ou não especiais". São considerados nesta categoria também: quartéis e bases militares; alojamentos e acampamentos; embarcações, barcos e navios; aldeias indígenas; penitenciárias, colônias penais, presídios e cadeias; asilos, orfanatos, conventos e hospitais (IBGE 2003:228-229).

6 Entre as diversas plataformas criadas pelo IBGE para a divulgação dos dados do Censo 2010 está um aplicativo web específico para os aglomerados subnormais. Nele é possível fazer buscas por estado, cidade, "nome do aglomerado" e acessar as informações levantadas para cada um dos setores censitários que o compõem: http://www.censo2010.ibge.gov.br/agsn/. 
7 "Morar" em uma casa, neste contexto etnográfico específico, se define por ter um lugar cotidiano para dormir e guardar roupas e outros pertences, como documentos, por exemplo.

8 Disponível em: http://www.fbb.org.br/tecnologiasocial/banco-de-tecnologias-sociais/pesquisar-tecnologias/detalhar-tecnologia-356.htm 


\section{Referências bibliográficas}

BURGOS, Marcelo. 1998. "Dos Parques Proletários ao Favela-Bairro". In: A. Zaluar \& M. Alvito (orgs.), Um século de favela. Rio de Janeiro: FGV Editora. pp. 25-60.

CARSTEN, Janet. 2003. After Kinship. Cambridge: Cambridge University Press.

CARSTEN, Janet \& HUGH-JONES, Stephen. 1995. "Introduction". In: (orgs.), About the house. Lévi-Strauss and beyond. Cambridge: Cambridge University Press. pp. 1-46.

CAVALLIERI, Fernando \& VIAL, Adriana. Favelas na cidade do Rio de Janeiro: o quadro populacional com base no Censo 2010. Rio de Janeiro: Instituto Pereira Passos. Disponível em: http:// portalgeo.rio.rj.gov.br/estudoscariocas/download\%5C3190_ FavelasnacidadedoRiodeJaneiro_Censo_2010. PDF. Acesso em: 12/03/2017

COHN, Bernard. 1996. Colonialism and its Forms of Knowledge: The British in India. Princeton: Princeton University Press.

DALMASO, Flavia. 2014. Kijan moun yo ye? As pessoas, as casas e as dinâmicas familiares em Jacmel/Haiti. Tese de Doutorado, PPGAS / Museu Nacional / UFRJ.

DESROSIÈRES, Alain. 1993. La politique des grandes nombres. Paris: Éditions Découverte.

DESROSIÈRES, Alain \& KOTT, Sandrine. 2005. "Quantifier". Genèses, 58 (1):2-3. Disponível em: https://doi. org/10.3917/gen.058.0002. Acesso em: 12/03/2017

ELIAS, Norbert. 1980. Introdução à sociologia. Braga: Edições 70.

GARCIA JR., Afrânio Raul. 1975. Terra de trabalho. Dissertação de Mestrado, PPGAS/ Museu Nacional/ UFRJ.
HACKING, Ian. 1990. The taming of chance. Cambridge: Cambridge University Press.

HEREDIA, Beatriz. 1979. A morada da vida. Rio de Janeiro: Paz e Terra.

IBGE. n/d. Glossário PNAD. IBGE. Disponível em: ftp://ftp.ibge.gov.br/ Trabalho_e_Rendimento/.../glossario_pnadc_mensal.pdf. Acesso em: 12/03/2017

1953. As favelas do Distrito Federal e o Censo Demográfico de 1950. Rio de Janeiro. mimeo. 2003. Metodologia do Censo Demográfico 2000. Rio de Janeiro: IBGE.

. 2011. Censo Demográfico 2010. Aglomerados Subnormais. Primeiros resultados. Rio de Janeiro: IBGE.

LÉVI-STRAUSS, Claude. 1982. The Way of the Masks. London: Jonathan Cape.

1984. Paroles données. Paris: Plon. 1987. Anthropology and Myth: Lectures 1951-1982. Oxford: Blackwell.

1991. "Maison". In: P. Bonté \& M. Izard (eds.), Dictionnaire de L'Ethnologie et de L'Anthropologie. Paris: PUF. pp. 434-436.

MACHADO DA SILVA, Luiz Antonio. 2002. "A continuidade do 'problema da favela'". In: L. L. Oliveira, Cidade: história e desafios. Rio de Janeiro: Editora FGV/CNPq. pp. 220-237.

. 2010. "'Violência urbana', segurança pública e favelas: o caso do Rio de Janeiro atual". Caderno CRH, 23 (59):283-300.

MARCELIN, Louis Herns. 1996. A invenção da família afro-americana: família, parentesco e domesticidade entre os negros do Recôncavo da Bahia, Brasil. Tese de Doutorado, 
PPGAS/ Museu Nacional/ UFRJ. 1999. "A linguagem da casa entre os negros no Recôncavo Baiano." Mana, 5 (2):31-60. Disponível em: https://dx.doi.org/10.1590/S010493131999000200002. Acesso em: $12 / 03 / 2017$

MILLER, Daniel. 2001. "Behind closed doors". In: D. Miller (org.), Home possessions. Material culture behind closed doors. Oxford, New York: Berg. pp 1-9.

MITCHELL, Timothy. 2002. Rule of Experts: Egypt, Techno-Politics, Modernity. Berkley: University of California Press.

MOTTA, Eugênia. 2010. Trajetórias e transformações no mundo da Economia Solidária. Tese de Doutorado, PPGAS / Museu Nacional/ UFRJ. . 2014. "Houses and economy in the favela". In: Vibrant - Virtual Brazilian Anthropology, v. 11, n. 1. January to June 2014. Brasilia, ABA.

. 2016. "Casas e economia cotidiana". In: Rute Rodrigues (org.), Vida social e política nas favelas: pesquisas de campo no Complexo do Alemão. Rio de Janeiro: Instituto de Pesquisa Econômica Aplicada - IPEA. pp. 197-214.

NEIBURG, Federico. 2011. "La guerre des indices. L'inflation au Brésil (19641994)". Gèneses, 84 (3):25-46.

. 2014. "Foucault em chave etnográfica: o governo dos guetos de Porto Príncipe". Análise Social, 212 (49):742-747. OBSERVATÓRIO DE FAVELAS; REDES DE DESENVOLVIMENTO DA MARÉ. 2012. Guia de Ruas. Maré.
Rio de Janeiro: Observatório das Favelas e Redes de Desenvolvimento da Maré.

PALMEIRA, Moacir. 1977. "Casa e trabalho: notas sobre as relações sociais na 'plantation' tradicional". Contraponto, 2 (2):103-114.

PORTER, Theodore. 1994. "Making Things Quantitative". Science in Context, 7:389-407.

. 1995. Trust in numbers: the pursuit of objectivity in science and public life. Princeton: Princeton University Press.

SCOTT, James. 1985. Weapons of the weak: everyday forms of resistance. New Haven and London: Yale University Press.

SILVA, Eliana Souza. 2002. "Censo Maré 2000: Uma experiência de coleta e geração de informações socioculturais e econômicas numa favela da cidade do Rio de Janeiro". Trabalho e Sociedade, 2 (3):15-20.

THÉVENOT, Laurent. 1995. "Cifras que falam: medida estatística e juízo comum". In: J. L. Besson, A ilusão das estatísticas. São Paulo: Unesp. pp. 149-161.

VALLADARES, Lícia. 2000. "A gênese da favela carioca - A produção anterior às ciências sociais". Revista Brasileira de Ciências Sociais, 15 (44):5-34. . 2005. A invenção da favela. Do mito de origem a favela.com. Rio de Janeiro: FGV.

WOORTMANN, Klaas. 1980. "Casa e família operária". Anuário Antropológico, 80:119-150. 


\section{RESISTÊNCIA AOS NÚMEROS: A \\ FAVELA COMO REALIDADE (IN) QUANTIFICÁVEL}

\author{
Resumo \\ Os grandes números, as estatísticas \\ estatais, são produzidos ao longo de \\ uma extensa cadeia de transformações \\ na qual se criam entidades de um tipo \\ particular: as realidades estatísticas. O \\ texto analisa uma realidade específica, a \\ favela, a partir de diferentes resistências \\ à sua quantificação. Mostro que estas \\ não interditam a produção dos números, \\ mas, pelo contrário, são mobilizadoras, \\ participando da criação do acordo \\ necessário para que se produzam \\ entidades consideradas reais. Também \\ demonstro, no caso das favelas, a relação \\ entre os dois sentidos da normalidade \\ em jogo nas estatísticas: aquilo que é \\ recorrente e o que é desejável e saudável. \\ Palavras-chave: Censo, Estatística, \\ Quantificação, Casa, Aglomerado \\ subnormal, Favela.
}

\section{RESISTING NUMBERS: THE FAVELA AS AN (UN)QUANTIFIABLE REALITY}

\begin{abstract}
Large numbers, state statistics, are produced along an extensive chain of transformations in which a particular kind of entity is created: statistical realities. The article analyses a specific reality, the favela, based on various resistances to its quantification. I show these resistances do not interdict the production of numbers but, on the contrary, they are mobilizers, participating in the creation of the necessary agreements to the construction of entities considered real. I also demonstrate, for the favelas, the relationship between the two meanings of normality at play in statistics: what is recurrent and what is considered desirable and healthy.

Keywords: census; statistics ; quantification; house; subnormal agglomerate; favela
\end{abstract}




\section{RESISTENCIA A LOS NÚMEROS:}

\section{LA FAVELA COMO REALIDAD (IN) CUANTIFICABLE}

\section{Resumen}

Los grandes números, las estadísticas estatales, son producidos a lo largo de una extensa cadena de transformaciones, en la cual son creadas entidades de un tipo particular: las realidades estadísticas. El texto analiza una realidad específica, la favela, a partir de las diversas resistencias a su cuantificación. Enseño que estas resistencias no impiden la producción de los números, por lo contrario, participan de la creación del acuerdo necesario para la creación de entidades consideradas reales. Además demuestro, en el caso de las favelas, la relación entre los dos sentidos de la normalidad en juego en las estadísticas: aquello que es recurrente y aquello que es deseable y saludable.

Palabras clave: Censo, Estadística, Cuantificación, Casa, Aglomerado subnormal, Favela. 